\title{
Knowledge, Attitude and Behavior of General Saudi Population toward Influenza Vaccine
}

\author{
Authors \\ Esraa S. Basabrain ${ }^{1}$, Lama R. Elessawi ${ }^{2}$, Mohammed S. Basubrain ${ }^{3}$, \\ Omar A. Bafarat ${ }^{4}$, Rana A. Baflah ${ }^{5}$, Rania M. Srouji ${ }^{6}$, Hassnah Omar Dammas ${ }^{7}$, \\ Omar Sami Basubrain ${ }^{8}$ \\ 1,2,3,4,5,6 Ministry of Health, Jeddah, KSA \\ ${ }^{7,8}$ King Abdullah Medical City (KAMC-HC), Makkah, KSA \\ Corresponding Author \\ Esraa Sami Basubrain \\ Email:Dr-soso06@hotmail.com
}

\begin{abstract}
Objectives: To determine the extent of the community awareness, knowledge and attitude toward influenza vaccine in Saudi Arabia.

Methods: a cross sectional online survey targeting general population in KSA.

Conclusion: The findings from this study suggest that majority of subjects knew about availability of influenza vaccine but poor knowledge and misconception about the vaccine led to decreased uptake which need to be corrected by combined effort of doctors, social media and awareness campaigns.

Keywords: Flu vaccine uptake, Influenza vaccine, knowledge about flu, attitude towards flu vaccine.
\end{abstract}

\section{INTRODUCTION}

Preventive Medicine is part of medicine that concerns the health of a person, community and a population. It aims to prevent disease and complications to maintain healthy life ${ }^{(1)}$. An essential part of this type of medicine is vaccination, which focuses on preventing infection by stimulating the immune system; Influenza vaccine is our concern in this study. Influenza is a viral infection that targets the URT and occasionally lungs. This virus is transmitted by droplet contact from an infected patient. The normal course of the disease is complete healing within one to two weeks, but at risk groups, including elderly, children and those who have medical chronic illness, are commonly complicated by pneumonia that may lead to death ${ }^{(2)}$. One study showed that among 310 patients who were hospitalized with pneumonia and influenza, 38 died, $79 \%$ had flu like symptoms, $68 \%$ were older than 65 years and $95 \%$ had chronic disease ${ }^{(3)}$. Fortunately, influenza vaccine can decrease the incidence of this complication by $80 \%$ in elderly ${ }^{(4)}$. Influenza vaccine is an ideal way in preventing disease or its complication. The vaccine covers 2 types of (A) strain and 2 types of (B) strain. Any other microbes that cause flu like symptoms are not included ${ }^{(4)}$. Previous studies involved the knowledge and attitude of health care workers (HCW) toward influenza vaccine. One of the studies done in the Middle East showed that uptake of the 
vaccine by the HCW was below standard ${ }^{(5)}$. Another study done in KSA for pregnant women also showed poor knowledge ${ }^{(6)}$ and other showed that physician had a poor influence on elderly and high-risk groups ${ }^{(7)}$. We need to focus on the education and awareness of the population about the vaccine, because lack of information can decrease the uptake of the vaccine.

\section{METHODS}

A cross sectional online survey was performed, 411 subjects responded, from general population in KSA through 3rd party agent. A 43-item questionnaire was used to record knowledge, attitude and preventive practices towards influenza vaccine among the general population; Subjects below 18 years old were excluded and most responses were from the Western region of KSA; responses were IP restricted to ensure single answer.

\section{RESULTS}

$64.72 \%$ (266) of participants were female. $78.83 \%$ of them were not working in medical field. All the subjects were over 18 years old. $69.83 \%$ had a bachelor degree, $12.17 \%$ had a postgraduate university degree and $15.09 \%$ with high school degree. In this population $28.95 \%$ had chronic disease, $9.49 \%$ had DM and $7.79 \%$ had asthma. $34.99 \%$ of tested population had previous education about influenza vaccine.

\section{A. Vaccination History}

$53.30 \%$ of the general population received the vaccine, $58.06 \%$ explain their reason as personal desire (table1) while the main reasons for not acquiring the vaccine is due to either lack of interest $(27.08 \%)$ or they were not convinced about the benefit of the vaccine $(29.17 \%)$ (table2).

$50 \%$ of females who were involved in the survey were pregnant or had been pregnant, with $20 \%$ of them reported that they had the vaccine during their pregnancy upon doctors advise in $30 \%$ or previous experience in another $30 \%$ (table1). On the other hand, $7.32 \%$ who didn't get the vaccine had one or more of the contraindications to the vaccine (table2). $28.37 \%$ of the tested population had a pregnant relative. $22.22 \%$ of them advised their pregnant relative to have the vaccine, As $50 \%$ of them knew that pregnant are a target group (table1) while 53.85\% who didn't advise their pregnant relative were afraid that it may affect the fetus (table2).

Out of $69.23 \%$ of tested population who have children, $37.98 \%$ of them vaccinated their children; $45.57 \%$ of parents explain their reason as personal desire (table 1), while the $31.58 \%$ who didn't give the vaccine to their children heard bad recommendations about it (table 2).

$40.40 \%$ of tested population advised their parents to have the vaccine because $57.75 \%$ knew that they are a target group (table1), while 30.73\% didn't advise their parents to get the vaccine due to inconvenience. (table2)

Table (1) Cause of receiving influenza vaccine

\begin{tabular}{|l|c|c|c|c|c|}
\hline & Population & $\begin{array}{c}\text { Current or Previous } \\
\text { Pregnancy }\end{array}$ & $\begin{array}{c}\text { Relative to } \\
\text { Pregnant }\end{array}$ & Children & Parents \\
\hline Doctor Advice & $16.67 \%$ & $30 \%$ & & $30.38 \%$ & $7.04 \%$ \\
\hline Upon My Wish & $58.06 \%$ & & & $45.57 \%$ & \\
\hline Previous Experience & $15.05 \%$ & $30 \%$ & & $12.66 \%$ & $22.54 \%$ \\
\hline Television & & $10 \%$ & & & \\
\hline For Hajj & $25.81 \%$ & & $50 \%$ & & $57.75 \%$ \\
\hline Known Target Group & & & $31.82 \%$ & $36.71 \%$ & \\
\hline Good Recommendation & & & $4.55 \%$ & $10.13 \%$ & $9.15 \%$ \\
\hline Friend Advice & & $30 \%$ & $13.64 \%$ & $11.39 \%$ & $16.90 \%$ \\
\hline Others & $10.75 \%$ & & & & \\
\hline
\end{tabular}




\section{JMSCR Vol||05||Issue||01||Page 15582-15587||January}

Table (2) Cause for refusing influenza vaccine

\begin{tabular}{|c|c|c|c|c|c|}
\hline & Population & $\begin{array}{c}\text { Current or Previous } \\
\text { Pregnancy }\end{array}$ & $\begin{array}{c}\text { Relative to } \\
\text { Pregnant }\end{array}$ & Children & Parents \\
\hline Bad Recommendation & $25 \%$ & & $19.23 \%$ & $31.58 \%$ & $23.39 \%$ \\
\hline Not Convinced & $29.17 \%$ & $14.63 \%$ & & $26.32 \%$ & $30.73 \%$ \\
\hline Lazy & $27.08 \%$ & & & & \\
\hline Ineffective Previous Vaccine & $3.65 \%$ & & & & $9.17 \%$ \\
\hline Previous Side-Effect & $4.69 \%$ & & & & $0.92 \%$ \\
\hline Did Not Get Advice & $11.46 \%$ & & $30.77 \%$ & $24.06 \%$ & $9.63 \%$ \\
\hline Contraindicated & $2.08 \%$ & $7.32 \%$ & & $2.26 \%$ & \\
\hline Expensive & $3.65 \%$ & & & $6.77 \%$ & \\
\hline Friend Advice & & $7.32 \%$ & $5.13 \%$ & $3.01 \%$ & $1.38 \%$ \\
\hline Social Media & & $7.32 \%$ & & & \\
\hline Fetal Side Effect & & & $53.85 \%$ & & \\
\hline Bad Experience & & & $3.85 \%$ & & \\
\hline Age $<6$ Months & & & & $3.01 \%$ & \\
\hline Others & $20.83 \%$ & $63.41 \%$ & $16.67 \%$ & $29.32 \%$ & $33.03 \%$ \\
\hline
\end{tabular}

\section{B. Methods of prevention:}

$65.01 \%$ of total population had previous knowledge about preventive methods of influenza; they received their information from social media and awareness campaigns in around $45 \%$ followed by doctors $(34.73 \%)$ (table 4). Out of those who had a previous knowledge about influenza prevention, $70 \%$ knew about method of prevention including the vaccine (Table 3 ).

Table 3 (preventive methods knowledge)

\begin{tabular}{|l|c|}
\hline Method & percentage \\
\hline Influenza vaccine & $72.14 \%$ \\
\hline Cover mouth & $77.86 \%$ \\
\hline Wash hands & $70.23 \%$ \\
\hline Sterilize surfaces & $62.60 \%$ \\
\hline Wear masks & $57.63 \%$ \\
\hline Eat healthy food & $57.25 \%$ \\
\hline other & $11.45 \%$ \\
\hline
\end{tabular}

Table (4) source of information of preventive methods of influenza, influenza vaccine awareness and availability in governmental PHC.

\begin{tabular}{|l|l|l|l|}
\hline $\begin{array}{l}\text { Source of } \\
\text { Information }\end{array}$ & $\begin{array}{l}\text { Method of } \\
\text { Prevention }\end{array}$ & $\begin{array}{l}\text { Influenza } \\
\text { Vaccine }\end{array}$ & $\begin{array}{l}\text { Availability at } \\
\text { PHC }\end{array}$ \\
\hline Doctor & $34.73 \%$ & $30.29 \%$ & $21.63 \%$ \\
\hline Friends & $15.27 \%$ & $23.71 \%$ & $15.51 \%$ \\
\hline Social Media & $45.80 \%$ & $41.71 \%$ & $36.73 \%$ \\
\hline Television & $27.10 \%$ & $20.86 \%$ & \\
\hline $\begin{array}{l}\text { Awareness } \\
\text { Campaigns }\end{array}$ & $43.51 \%$ & $21.71 \%$ & \\
\hline Leaflets & $23.28 \%$ & $18 \%$ & $8.16 \%$ \\
\hline Posters & $26.72 \%$ & $25.14 \%$ & $28.16 \%$ \\
\hline Visiting PHC & & & $31.02 \%$ \\
\hline Others & $19.47 \%$ & $18.29 \%$ & 22.04 \\
\hline
\end{tabular}

\section{Vaccination Knowledge}

$86.60 \%$ of total population know about influenza vaccine, $41.71 \%$ received this information from social media, and $30.29 \%$ from a doctor. (table 4 ).

Regarding the knowledge of general population toward target groups for influenza vaccine; $54.73 \%$ thought that pilgrim and workers in al-hajj, $46.99 \%$ health care worker and $26.36 \%$ pregnant women are among high risk group (Table5), and 61.60\% believed that all the society should get the vaccine. (table5)

Table 5 (target group and who should get the vaccine)

\begin{tabular}{|l|c|c|}
\hline & Target & Should get \\
\hline Health worker & $46.99 \%$ & $28.08 \%$ \\
\hline Elderly & $41.26 \%$ & $30.66 \%$ \\
\hline Pregnant & $26.36 \%$ & $18.91 \%$ \\
\hline Chronic patient & $29.23 \%$ & $24.93 \%$ \\
\hline Children & $44.41 \%$ & $36.39 \%$ \\
\hline Hajj worker and pilgrim & $54.73 \%$ & $41.83 \%$ \\
\hline AIDS & $33.81 \%$ & $25.21 \%$ \\
\hline Tumors patient & $17.77 \%$ & $12.89 \%$ \\
\hline All society & $49.86 \%$ & $61.60 \% \%$ \\
\hline
\end{tabular}

Regarding contraindications of influenza (CI) $63.32 \%$ though that fever is a CI and $21.49 \%$ thought that pregnancy is. (table 6) 
Table 6 (flu vaccine contraindications)

\begin{tabular}{|l|c|}
\hline Contraindication & percentage \\
\hline Fever & $63.32 \%$ \\
\hline Guillain-Barre syndrome & $17.19 \%$ \\
\hline Egg allergy & $26.65 \%$ \\
\hline History of allergy against vaccine & $42.12 \%$ \\
\hline Age <6 month & $36.96 \%$ \\
\hline Pregnancy & $21.49 \%$ \\
\hline AIDS & $7.74 \%$ \\
\hline Tumor patient & $6.59 \%$ \\
\hline other & $13.18 \%$ \\
\hline
\end{tabular}

$80.80 \%$ of total population though that the vaccine is available as injection, $2.58 \%$ as nasal spry and $1.94 \%$ only chose both methods of administration. $63.90 \%$ believe that they should receive the vaccine annually, and $71.35 \%$ will take it the future, also $73.35 \%$ will advise other to take it.

\section{Governmental Services}

$70.20 \%$ of total population knew that the influenza vaccine is available in all governmental primary health care centers, and $36.73 \%$ receive information from social media (table 4).

\section{DISCUSSION}

Influenza vaccine is effective in decreasing infection incidence, complications such as pneumonia and death. United States Statistics that began in 1900 until present showed death rate was 200 per 100,000 and had slowly declined over the years to reach nearly 20 to 25 per 100,000 by 1970 s when influenza vaccines initially emerged(8).

According to centers of disease control and prevention "routine annual influenza vaccination of all persons aged 6 months or older without contraindications continues to be recommended" (9). Despite that; $86.60 \%$ of tested population who knew about influenza vaccine, and most of them believed that all society individual should get the vaccine only half of them received it. Part of them explain their reason is laziness whitch can be solved by the new governmental service available in KSA to deliver the vaccine needed to individuals by (Careem) transport system for a small fee, on the other hand this should be advertised to deliver this information to general population.
The remaining subjects with $13.40 \%$ had no previous idea about existence of influenza vaccine. Furthermore, even after sub-analysis both healthy subjects and those with chronic disease had almost the same knowledge regarding existence of vaccine. Although more than half of our tested population had children, only a small percentage gave their children the vaccine. On the other hand, those who didn't give vaccine to their children was because of bad reputations about vaccine, almost the same percentage found in parents whom were given advice to have the vaccine.

The centers for disease control and prevention's advisory committee on immunization practices (ACIP) and the American collage of obstetricians and gynecologists recommend that all women who are or will be pregnant during the influenza session have an influenza vaccine as soon as possible. All current available data overwhelmingly support the safety of influenza vaccination during pregnancy ${ }^{(7)}$. In our study we found that uptake of flu vaccine among pregnant women varies due to a misconception that it may harm the fetus.

As a result; misconception and lack of knowledge were the main obstacles to achieve acceptance of influenza vaccine.

Influenza virus may affect any individual; certain groups are at higher risk of developing serious complications of infection and these are patients with chronic diseases, immunocompromised patient, elderly, children, pregnant women, those planning for Hajj or Umrah and healthcare workers ${ }^{(10)}$. In our study it was agreed that health care worker are among highest risk group followed by elderly and children, and they knew that vaccine contraindications mostly are fever, history of allergy to previous influenza vaccine and children below 6 months old.

The two routes of administration of influenza vaccine are Intramuscular injection and Intranasal spray application ${ }^{(4)}$, in our study IM route of administration was the most convenient method while very few subjects agreed that flu vaccine can be given by both routes. 
Regarding methods of prevention, more than half of tested population had reasonable knowledge about methods of prevention, they mainly acquired it through social media, awareness campaign and doctors; they were aware that covering the mouth and nose while coughing, taking the vaccine and washing their hands after touching patients have the highest efficacy in prevention.

Subjects were committed toward annual uptake of influenza vaccine and they are encouraging others to get it, also most of population know that influenza vaccine is available at governmental primary health centers.

Misconception and lack of knowledge were the main obstacles to achieve optimal uptake of the vaccine.

Even though there are many different channels of information (doctors, awareness campaigns), there is insufficient information about the effectiveness of the vaccine and many misconceptions regarding side effects. Moreover, as had been shown also in another study ${ }^{(11)}$, we found that doctors' participation in delivery of such information remains low.

\section{COCLUSION}

In conclusion, majority of the Saudi population had effective knowledge about the availability of the influenza vaccine. However, the misconceptions about the harm caused by the vaccine decreased the uptake of the vaccine.

We recommend a combined approach by awareness programs, doctors, and social media. This would disseminate the correct information about the vaccine, and provide a communication channel if people had any queries about the benefits and risks of vaccination. This would increase the uptake of the vaccine in the general population and ensure the delivery of correct information.

\section{REFERENCES}

1. American Board of Preventive Medicine, last accessed on 11 Jan. 2017 at https://www.theabpm.org/aboutus.cfm
2. World Health Organization, Influenza, last accessed on 11 Jan. 2017 at http://www.who.int/topics/influenza/en/

3. Barker WH, Mullooly JP. Pneumonia and Influenza Deaths During Epidemics Implications for Prevention. Arch Intern Med. 1982;142(1):85-89. doi:10.1001/archinte.1982.00340140087016

4. Ministry of Health, Kingdom of Saudi Arabia, Seasonal Influenza Vaccination, last accessed at 11 Jan. 2017 at http://www.moh.gov.sa/en/Flu/Pages/Prevention.aspx

5. Abu-Gharbieh E, Fahmy S, Rasool BA, Khan S. Influenza Vaccination: Healthcare Workers Attitude in Three Middle East Countries. Int J Med Sci 2010; 7(5):319-325. doi:10.7150/ijms.7.319 http://www.medsci.org/v07p0319.htm

6. Mayet, A.Y. et al., Knowledge, attitudes, beliefs, and barriers associated with the uptake of influenza vaccine among pregnant women. Saudi Pharmaceutical Journal (2016) http://dx.doi.org/10.1016/j.jsps.2015.12.001

7. Nichol KL, Zimmerman R. Generalist and Subspecialist Physicians' Knowledge, Attitudes, and Practices Regarding Influenza and Pneumococcal Vaccinations for Elderly and Other High-Risk PatientsA Nationwide Survey. Arch Intern Med. 2001;161 (22): 2702-2708. doi:10.1001/archinte.161.22.2702

8. Global Research, Effectiveness of Flu Vaccine Against Influenza, last accessed on 11 Jan. 2017 at http://www.globalresearch.ca/effectiveness-of-the-flu-vaccineagainst-influenza/5376190

9. Center of Disease Control and Prevention, Prevention and Control of Seasonal Influenza with Vaccines, last accessed on 11 Jan. 2017 at https://www.cdc.gov/flu/professionals/acip/index.htm

10. Ministry of Health, Kingdom of Saudi Arabia, Seasonal Influenza Vaccination, last accessed on 11 Jan. 2017 at http://www.moh.gov.sa/en/Flu/Pages/Categories.aspx 
11. Mohammad Sami Basubrain, Esraa Sami Basubrain, Lama Rashid Elessawi, Omar Ahmed Bafarat, Rana Abdulrahman Baflah, Rania Mohammed Srouji, Omar Sami Basubrain, Hassnah Omar Dammas, Knowledge, Attitude, and Practice of General Population Towards CVD in Saudi Arabia, Journal of Medical Science and Clinical Research, accessed last on 11 Jan. 2017 doi: https://dx.doi.org/10.18535/jmscr/v4i12.127. 